\title{
Hematological differences in newborn and aging: a review study
}

\begin{abstract}
The aim of this study was to highlight the possible cause of hematological differences in newborn and aging for appropriate hematological reference values to be used for treatment at all developmental stages. The neonate (newborn infant) older child and adult exhibit profound hematologic differences from one another because children mature at different rates, quantitative and qualitative differences are present as a reflection of the developmental changes during fetal hematopoiesis which correlate with gestational age. At birth, hematological of term newborns are significantly higher than those of older children and adults and in preterm neonates the differences are even more pronounced. It is inappropriate to use adult reference ranges for the assessment of pediatric blood values. Geriatric medicine is a rapidly growing branch of medicine, care of the elderly has become a growing trend as the life expectancy of the population continues to increase. Hematological changes are obvious in both the neonates and the elderly persons and at such; different hematological variables must be implemented in various developmental stages of the neonates as well as the different classes of aged elderly individuals. Also among the elderly, certain hematological disorders are more common which need urgent attention of their physicians. This review highlighted some major factors that responsible for hematological differences in newborn and aging.
\end{abstract}

Volume 3 Issue 3 - 2016

\author{
Esan Ayodele Jacob \\ Department of Hematology and Blood Transfusion Science, \\ Federal Teaching Hospital, Nigeria
}

Correspondence: Esan Ayodele Jacob, Federal Teaching Hospital, Nigeria, Email ayodelejacob4u@gmail.com

Received: November 25, 2016 | Published: December 28, 2016

Keywords: hematological differences, newborn, aging, hematopoiesis, lymphocytes, hemoglobin, neutrophils, leukemia

Abbreviations: $\mathrm{MCV}$, mean cell volume; $\mathrm{CBC}$, complete blood count; $\mathrm{Hb}$ F, fetal hemoglobin; $\mathrm{RBC}$, red blood cell; $\mathrm{MCH}$, mean cell hemoglobin; MCHC, mean cell hemoglobin concentration; RDW, red blood cell distribution width; ALL, acute lymphoblastic leukemia; PAI, plasminogen activator inhibitor; 2,3-BPG, 2,3-bisphosphoglycerate concentration; CLL, chronic lymphocytic leukemia

\section{Introduction}

A newborn represents the culmination of developmental events from conception and implantation through organogenesis. The embryo requires red cells for the transport of maternal oxygen to permit this growth and development. Birth brings dramatic changes in circulation and oxygenation, which affects hematopoiesis, as the newborn makes the transition to a separate biological existence. During embryogenesis, hematopoiesis occurs in distinct sites, including the extra embryonic yolk sac, the fetal liver and the preterm bone marrow. Erythropoiesis is established soon after implantation of the blastocyst, with primitive erythroid cells appearing in yolk sac blood islands by day 18 of gestation. ${ }^{1}$ Pediatric hematology has emerged as a specialized science with age-specific reference ranges that correlate with the hematopoietic, immunologic and chemical changes in a developing child. Dramatic changes occur in the blood and bone marrow of the newborn infant during the first hours and days after birth and there are rapid fluctuations in the quantities of all hematologic elements. According to ${ }^{2}$ reported that, the values of most of the hematological parameters studied were highest especially hemoglobin concentration, packed cell volume, reticulocyte count and red cell indices on the first day of life and thereafter declined over the third day and the sixth week of life as shown in Table 1-3. This declined in hematological parameters was reported in other studies done in Nigeria. ${ }^{3}$ Similarly, Caucasian infants also showed the same pattern of steady decline in the hemoglobin concentration. ${ }^{4-7}$ Factor contributing to decline in hematological parameters in the newborn was due to decrease in blood erythropoietin concentration soon after birth, reducing the erythropoietic rate. Also, transient hemolysis is high during the first days or week after birth as during the remainder of healthy life, this transient hemolysis is a general physiologic occurrence during the first week after birth similar to neocytolysis a rapid decline in hemoglobin, because of hemolysis, seen in mountaineers after they descend to sea level following many weeks at high altitude. ${ }^{8-12}$ Significant hematologic differences are seen between term and preterm infants and among newborns, infants, young children and older children. The life expectancy and quality of life of the elderly have improved dramatically in recent years. Global aging is occurring at a record breaking rate. Although age 65 is considered the mean geriatric age, this age is constantly rising to age 122 as the upper limit. World Health Organization reports that by 2050 , one fifth of the global population will be adults 65 years and older. ${ }^{13}$ The hematopoietic system is modestly affected by ageing and these effects become particularly notable after age 65 . There is a continuous decrease in the volume of the hematopoietic marrow with age, which does not cause significant alterations in either granulocyte, monocyte or platelet counts, although a slight decrease in population mean hemoglobin level or hematocrit in men after middle age. However, hemoglobin levels in women may increase slightly with age or remain unchanged. Decrease in hemoglobin level between older men and women may be the result of decrease androgen level in older men and decrease in estrogen levels in older women. Iron deficiency and anemia of chronic disease have usually been responsible for low hemoglobin level in majority of asymptomatic elderly people. Decrease immune cell function is the most consistent change in the older persons; this change affects both cellular immune functions and antibody responses to antigens because of the T-helper cell function 
required. The elderly can be roughly divided into three age categories: the young- old age 65 to 74 , the old-old age 74 to 84 and the very old age 85 and older. Disease and disabilities are not a function of age, although age may be a risk factor for many diseases. With the increase in the aging population, the incidence of age related health conditions also is likely to increase. Inappropriate reference values may lead to unnecessary testing and investigations or more importantly, they may fail to detect a critical underlying disease. A growing concern about the interpretation of hematologic data in context with age is due partly to the tremendous heterogeneity of the aging process and partly to the difficulty in separating the effects of age from the effects of occult diseases that accompany aging. ${ }^{14}$ Hematological values in neonates differ significantly from those in older children and adults. Quantitative and qualitative differences are present as a reflection of the developmental changes during fetal hematopoiesis and so, correlate with gestational age. ${ }^{15}$ This article reviews neonatal and aging hematopoiesis, as a prerequisite to understanding the differences in pediatric and geriatric hematologic reference ranges, morphologic features and age-specific physiology.

Table I Hematological values in low birth weight infants

\begin{tabular}{|c|c|c|c|c|c|c|}
\hline \multicolumn{7}{|c|}{ Age of infant with birth weight less than $1200 \mathrm{~g}$} \\
\hline parameters & I-3days & 4-7days & 2weeks & 4weeks & 6weeks & 8 weeks \\
\hline Hemoglobin & 15.6 & 16.4 & 15.5 & 11.3 & 8.5 & 7.8 \\
\hline Retics(\%) & 8.4 & 3.9 & 1.9 & 4.1 & 5.4 & 6.1 \\
\hline Platelet & 148000 & 163000 & 162000 & 158000 & 210000 & 212000 \\
\hline TWBC & 14800 & 12200 & 15800 & 13200 & 10800 & 9900 \\
\hline Seg. neutrophil & 46 & 32 & 41 & 28 & 23 & 23 \\
\hline Band neutrophil & 10.7 & 9.7 & 8 & 5.9 & 5.8 & 4.4 \\
\hline Juvenil neutrophil & 2 & 3.9 & 5.3 & 3.6 & 2.6 & 2 \\
\hline Lymphocytes & 32 & 43 & 39 & 55 & 61 & 65 \\
\hline Monocytes & 5 & 7 & 5 & 4 & 6 & 3 \\
\hline Eosinophil & 0.4 & 6.2 & I & 3.7 & 2 & 3.8 \\
\hline Nucleated RBC & 16.7 & I.I & 0.1 & 1 & 2.7 & 2 \\
\hline \multicolumn{7}{|c|}{ Birth weight between I200g and I500g } \\
\hline Hemoglobin & 20 & 18 & 17.1 & 12 & 9.1 & 8.3 \\
\hline Retics(\%) & 2.7 & 1.2 & 0.9 & 1 & 2.2 & 2.7 \\
\hline Platelet & 151000 & 134000 & 153000 & 189000 & 212000 & 244000 \\
\hline TWBC & 10800 & 8900 & 14300 & 11000 & 10500 & 9100 \\
\hline Seg. neutrophil & 47 & 31 & 33 & 26 & 20 & 25 \\
\hline Band neutrophil & 11.9 & 10.5 & 5.9 & 3 & I. 4 & 2.1 \\
\hline Juvenil neutrophil & 5.1 & 2.4 & 2.7 & 1.8 & 1.7 & 1.6 \\
\hline Lymphocytes & 34 & 48 & 52 & 59 & 69 & 64 \\
\hline Monocytes & 3 & 6 & 3 & 4 & 5 & 5 \\
\hline Eosinophil & 1.3 & 2.2 & 2.5 & 5.1 & 2.6 & 2.3 \\
\hline Nucleated RBC & 19.8 & 0.8 & 0 & 0.4 & 1.4 & I \\
\hline
\end{tabular}

Table 2 Hematologic values for very low birth weight infants during the first 6 weeks of life

\begin{tabular}{lllll}
\hline Age of infant(days) & & & & \\
\hline Hematologic value & $\mathbf{3}$ & $\mathbf{1 2 - 1 4}$ & $\mathbf{2 4 - 2 6}$ & $\mathbf{4 0 - 4 2}$ \\
\hline Hemoglobin(g/dL) & 15.6 & 14.4 & 12.4 & 10.6 \\
Hematocrit(\%) & 47 & 44 & 39 & 33 \\
Red Blood Cells(x10\%/L) & 4.2 & 4.1 & 3.8 & 3.4 \\
Reticulocytes(\%) & 7.1 & 1.7 & 1.5 & 1.8 \\
Platelet(x|0\%/L) & 203.5 & 318 & 338 & 357 \\
White Blood Cells $\left(\times 10^{9} / \mathrm{L}\right)$ & 9.5 & 12.3 & 10.4 & 9.1 \\
\hline
\end{tabular}


Table 3 Red cell indices of the babies on first day, third day and sixth weeks of life

\begin{tabular}{|c|c|c|c|}
\hline parameters & Day I $(n=\mid 80)$ Mean \pm SD(Range) & Day 3(n=|73) Mean \pm SD(Range) & Week $6(n=\mid 42)$ Mean \pm SD(Range) \\
\hline $\operatorname{pcv}(\%)$ & $46.3 \pm 7.2(30-68)$ & $43.3 \pm 7.7(30-64)$ & $32.0 \pm 4.8(23-48)$ \\
\hline $\mathrm{Hb}(\mathrm{g} / \mathrm{dl})$ & $15.4 \pm 2.4(9.4-22.7)$ & $14.5 \pm 2.6(8.0-22.1)$ & $10.6 \pm 1.7(7.7-15.9)$ \\
\hline $\mathrm{RBC}(\times 10 / \mathrm{I})$ & $5.1 \pm 0.8(3.2-7.6)$ & $4.8 \pm 0.9(2.7-7.5)$ & $3.9 \pm 0.6(1.3-5.9)$ \\
\hline $\operatorname{MCV}(\mathrm{fL})$ & $91.6 \pm 7.2(73.0-110.0)$ & $89.9 \pm 6.8(74.0-104.0)$ & $80.4 \pm 8.3(62.0-99.0)$ \\
\hline $\mathrm{MCH}(\mathrm{pg})$ & $30.5 \pm 2.6(24.0-36.0)$ & $29.9 \pm 2.5(23.5-35.9)$ & $26.6 \pm 2.8(20.8-34.1)$ \\
\hline $\mathrm{MCHC}(\mathrm{g} / \mathrm{dl})$ & $33.1 \pm 1.4(25.9-36.1)$ & $33.0 \pm 1.3(23.5-35.9)$ & $32.7 \pm 1.3(25.9-36.7)$ \\
\hline $\mathrm{nRBC}(\%)$ & $4.3 \pm 8.8(0.0-48.0)$ & $1.5 \pm 4.5(0.0-30.0)$ & $0.6 \pm 2.2(0.0-20.0)$ \\
\hline Retic(\%) & $3.5 \pm 1.4(0.0-7.1)$ & $2.6 \pm 1.5(0.0-6.0)$ & $2.7 \pm 1.7(0.0-8.4)$ \\
\hline
\end{tabular}

\section{Prenatal hematopoiesis}

Hematopoiesis is the formation and development of blood cells from stem cells, begins in the first weeks of embryonic development and proceeds systematically through three phases of development: mesoblastic (yolk sac), hepatic (liver) and myeloid (bone marrow). The first cells produced in the developing embryo are primitive erythroblasts formed in the yolk sac. These cells are particularly interesting because they do not develop into mature erythrocytes. They are erythropoietin insensitive and have the ability to differentiate into other cell lines upon exposure to appropriate growth factors. Primitive erythroblasts are characterized by more rapid maturation, increased sensitivity to erythropoietin and a shortened life span compared to fetal and adult erythroblasts. ${ }^{16}$ Yolk sac erythroblasts are extremely large red cells (megaloblasts) with an estimated mean cell volume (MCV) of $>450 \mathrm{fl} / \mathrm{cell}$. By the second month of gestation, hematopoiesis ceases in the yolk sac and the liver becomes the center for hematopoiesis, reaching its peak activity during the third and fourth gestational months. Liver serves as the primary source of red cells production from the $9^{\text {th }}$ to the $24^{\text {th }}$ weeks of gestation, during this weeks of gestation, embryo requires red cells for the transport of maternal oxygen to permit growth and development, birth brings dramatic changes in circulation and oxygenation which affects hematopoiesis as the newborn makes the transition to separate biological existence. Leukocytes of each cell type systematically make their appearance. In week 9 of gestation, lymphocytes can be detected in the region of the thymus. They are subsequently found in the spleen and lymph nodes. In contrast to the yolk sac, where hematopoiesis is restricted to erythroid and macrophage cells, hematopoiesis in the fetal liver also includes other myeloid as well as lymphoid lineages. Mega karyocytes are present in the liver by 6 weeks of gestation. Platelets are first evident in the circulation at $8-9$ weeks gestation. Small numbers of circulating leukocytes are present at the $11^{\text {th }}$ week of gestation. ${ }^{1}$ Granulopoiesis is present in the liver parenchyma and in some areas of connective tissue as early as 7 weeks gestation. During the fourth and fifth gestational months, the bone marrow emerges as a major site of blood cell production and it becomes the major and primary site of hematopoiesis after the $24^{\text {th }}$ week of gestation till birth. Initially there are approximately equal numbers of myeloid and erythroid cells in the fetal marrow. However, myeloid cells predominate by 12 weeks gestation and the myeloid to erythroid ratio approaches the adult level of 3 to 1 by 21 weeks gestation. ${ }^{16}$

\section{Hematopoiesis of the newborn}

Hematopoietic active of bone marrow is referred to as red marrow, as opposed to inactive yellow (fatty) marrow. At the time of birth, the bone marrow is fully active and extremely cellular, with all hematopoietic cell lineages undergoing cellular differentiation and amplification. In addition to the mature cells in fetal blood, there are significant numbers of circulating progenitor cells in cord blood. In a full-term infant, hepatic hematopoiesis has ceased except in widely scattered small foci that become inactive soon after birth. Postembryonic extra medullary hematopoiesis is abnormal in a full-term infant. In a premature infant, foci of hematopoiesis are frequently seen in the liver and occasionally observed in the spleen, lymph nodes or thymus. ${ }^{17}$

\section{Gestational age and birth weight}

Hematologic values obtained from full-term infants generally do not apply to preterm infants and laboratory values for low-birthweight preterm infants differ from ranges for extremely-low-birthweight "micro preemies" (24 to 26weeks gestation) as shown in Table 1. A full-term infant is defined as an infant who has completed 37 to 42 weeks of gestation. Infants born before 37 weeks gestation are referred to as premature or preterm, whereas infants delivered after 42 weeks are considered post term. Infants can be subcategorized further by birth weight as

i. Appropriate size for gestational age

ii. Small for gestational age, including low-birth-weight infants (2500g or less)

iii. Very-low-birth-weight infants (1500g or less)

iv. Extremely-low-birth-weight micro preemies (500g or less) and

v. Large for gestational age (more than $4000 \mathrm{~g})^{16}$

In the neonatal period the complete blood count ( $\mathrm{CBC}$ ) highly correlates with gestational age, birth weight, blood sampling site, crying, physical therapy, mode of delivery.

\section{Pediatric developmental Stages}

Pediatric hematologic values change markedly in the first weeks and months of life. As a result, many variables influence the interpretation of what might be considered normal values at the time of birth. It is important to provide age-appropriate pediatric hematology values that extend from neonatal life through adolescence. The pediatric population can be categorized with reference to three different developmental stages:

i. The neonatal period, which represents the first 4 weeks of life

ii. Infancy, which incorporates the first year of life and 
iii. Childhood, which spans age 1 to puberty (age 8 to 12years)

iv. Preterm, low-birth-weight infants are more apt to develop health problems than are other newborns ${ }^{16}$ Since 1990s, the rising quality of medical care in neonatal intensive care units has improved markedly the survival of smaller infants born at younger gestational ages with less mature hematopoietic systems $^{18}$

\section{Synthesis of fetal hemoglobins}

Human hemoglobin is a tetramer composed of two $\alpha$-type and two $\beta$-type globin chains. The $\alpha$-globin gene cluster is located on chromosome 16 and contains the $\mathrm{z}$ gene 5 ' to the pair of $\alpha$-globin genes. The $\beta$-globin gene cluster is located on chromosome 11 and contains five globin genes oriented 5' to 3'. During embryogenesis the genes on both chromosomes are activated sequentially from the 5 ' to the 3' end. This globin "switching" is related not only to the relative positions of the globin genes within their respective chromosomal clusters, but also to interacting upstream locus control regions.

\section{Embryonic hemoglobin}

Erythroid precursors are macrocytic resulting into generation of nucleated RBCs containing embryonal hemoglobins. Embryonic Hemoglobin is a tetramer produced in the blood islands in the embryonic yolk sac during the mesoblastic stage (first week of pregnancy until the end of the pregnancy). The protein is commonly referred to as Hemoglobin $\varepsilon$. Chromosomal abnormalities can lead to a delay in switching from embryonic hemoglobin ${ }^{19}$ there are different types of embryonic hemoglobin:

Hemoglobin gower 1: (as $\zeta_{2} \varepsilon_{2}$ or $\mathrm{HbE}$ Gower 1) does a form of hemoglobin exist only during embryonic life and is the primary and major hemoglobin in embryos less than 5 weeks of gestation. It is composed of two zeta chains and two epsilon chains and is relatively unstable, breaking down easily. ${ }^{20}$

Hemoglobin gower 2: $\left(\alpha_{2} \varepsilon_{2}\right.$ or $\mathrm{HbE}$ Gower 2) is a form of hemoglobin existing at low levels during embryonic and fetal life. It has been found in embryos with a gestational age as young as 4week and is absent in embryos older than 13week. It is composed of two alpha chains and two epsilon chains and is somewhat unstable, though not as much as hemoglobin Gower 1. Due to its relative stability compared to hemoglobin Gower 1 and hemoglobin S, it has been proposed as a subject for reactivation in the adult in cases of severe $\beta$-thalassemia and hemoglobinopathies in subjects for which the reactivation of hemoglobin $\mathrm{F}$ is contraindicated due to toxicity concerns. ${ }^{20}$

Hemoglobin portland $\mathbf{I}:\left(\zeta_{2} \gamma_{2}\right.$ or $\mathrm{HbE}$ Portland 1$)$ is a form of hemoglobin existing at low levels during embryonic and fetal life, composed of two zeta chains and two gamma chains. ${ }^{20}$ It is found in young embryos but persists in infants with homozygous $\alpha$-thalassemia. Synthesis of $\zeta$ and $\varepsilon$ chains decreases as that of $\alpha$ and $\beta$ chain increases

Hemoglobin portland II: $\left(\zeta_{2} \beta_{2}\right.$ or $\mathrm{HbE}$ Portland 2) is a form of hemoglobin existing at low levels during embryonic and fetal life, composed of two zeta chains and two beta chains. It is quite unstable, more so than even hemoglobin Gower 1 and breaks down very rapidly under stress. Despite this, it has been proposed as a candidate for reactivation in cases of severe $\alpha$-thalassemia or hemoglobinopathies afflicting the alpha chain. ${ }^{20}$

Fetal hemoglobin $\left(\boldsymbol{\alpha}_{2} \gamma_{2}\right)$ : It is the major hemoglobin of fetal life, synthesis of hemoglobin A can be in fetuses as young as 9 weeks of gestation. In fetuses of 9 to 21 weeks of gestation, the amount of $\mathrm{Hb} \mathrm{A}$ $\left(\alpha_{2} \beta_{2}\right)$ rises from 4 to 13 percent of the total hemoglobin. ${ }^{1}$ These levels of $\mathrm{Hb}$ A have enabled the antenatal diagnosis of $\beta$-thalassemia using globin chain synthesis. After 34 to 36 weeks of gestation the percentage of $\mathrm{Hb} \mathrm{A}\left(\alpha_{2} \beta_{2}\right)$ rises, while that of $\mathrm{Hb} \mathrm{F}\left(\alpha_{2} \gamma_{2}\right)$ decreases. The amount of $\mathrm{Hb} \mathrm{F}$ in blood varies in term infants from 53 to 95 percent of total hemoglobin. The fetal hemoglobin concentration in blood decreases after birth by approximately 3 percent per week and is generally less than 2 to 3 percent of the total hemoglobin by 6 months of age. This rate of decrease in $\mathrm{Hb} \mathrm{F}$ production is closely related to the gestational age of the infant and is not affected by the changes in environment and oxygen tension that occur at the time of birth. $\mathrm{Hb} \mathrm{A}_{2}\left(\alpha_{2} \delta_{2}\right)$ has not been detected in fetuses. Normal adult levels of $\mathrm{Hb} \mathrm{A}_{2}$ are achieved by four months of age. Increased proportions of $\mathrm{Hb} \mathrm{F}$ at birth have been reported in infants who are small for gestational age, who have experienced chronic intrauterine hypoxia, or who have trisomy 13 also decreased levels of $\mathrm{Hb} \mathrm{F}$ at birth are found in trisomy 21. Persistence of the embryonic $\mathrm{Hb}$ Gower 1, Hb Gower 2 and $\mathrm{Hb}$ Portland has been described in some infants with developmental abnormalities, while persistently elevated levels of fetal hemoglobin have been observed in infants dying from the sudden infant death syndrome. ${ }^{1}$

\section{Fetal blood}

The fetal blood composition changes markedly during the second and third trimesters. The mean hemoglobin in fetuses progressively increases from $9.0 \pm 2.8 \mathrm{~g} / \mathrm{dl}$ at age 10 weeks to $16.5 \pm 4.0 \mathrm{~g} / \mathrm{dl}$ at 39 weeks. There is a decrease in the MCV of fetal red cells from a mean 134fi/ cell at 18 weeks and $118 \mathrm{fl} /$ cell at 30 weeks gestation. The total white blood cell count during the middle trimester is between 4 and $4.5 \times 10^{9} /$ liter, with an 80 to 85 percent preponderance of lymphocytes and 5 to 10 percent neutrophils. The percentage of circulating nucleated red cells decreases from a mean of 12 percent at 18 weeks to 4 percent at 30 weeks. The platelet count remains greater than $150,000 / \mu 1$ from 15 weeks gestation to term.

\section{Red blood cell values at birth}

Neonatal hematological values are affected by the gestational age of the infant, the age in hours after delivery, the presence of illness and the level of support required. Other important variables to be considered when evaluating laboratory data include site of sampling and technique (capillary versus venous puncture, warm or unwarmed extremity), timing of sampling and conditions such as the course of labor and the treatment of the umbilical vessels. ${ }^{16}$ The presence of fetal hemoglobin ( $\mathrm{Hb} \mathrm{F}$ ), bilirubin and lipids in newborns can also interfere with hematology laboratory testing. ${ }^{1}$

\section{Red blood cell (RBC) count}

The RBC count increases during the first 24hours of life, remains at this plateau for about 2 weeks and then slowly declines. This "polycythemia of the newborn" may be explained by in utero hypoxia, which becomes more pronounced as the fetus grows. Hypoxia, the trigger for increased secretion of erythropoietin, stimulates erythropoiesis. At birth, the physiologic environment changes and the fetus makes the transition from its placenta-dependent oxygenation to the increased tissue oxygenation of the lungs. This increased oxygen tension suppresses erythropoietin production, which is followed by a decrease in RBC and hemoglobin production, ${ }^{21}$ Normal development of human fetal hematopoiesis between eight and seventeen weeks gestation. Studies show that erythropoietin levels before birth are equal to or greater than adult levels with a gradual drop to near zero a few weeks after birth; $; 2$ this decline corresponds to the physiologic 
anemia seen at 5 to 8 weeks of life, with the RBCs reaching their lowest count at 7 weeks of age and hemoglobin reaching its lowest concentration at 9 weeks of age. The span of erythrocytes in full term infants is shorter than that of adult erythrocytes; the life span of RBCs in premature infants is considerably shorter. The more immature the infant is the greater the degree of reduction.

\section{Red blood cell morphology of the neonate}

Early normoblasts are megaloblastic, hypochromic and irregularly shaped. During hepatic hematopoiesis, normoblasts are smaller than the megaloblasts of the yolk sac but are still macrocytic. Erythrocytes morphology remains macrocytic from the first 11 weeks of gestation until day 5 of postnatal life. ${ }^{23}$ The macrocytic RBC morphology gradually changes to the characteristic normocytic normochromic morphology. Orthochromic or polychromasia normoblasts frequently are observed in the full term infant on the first day of life but disappear within post natal days three to five. Nucleated RBC may persist longer than a week in immature infants. The presence of nucleated RBCs for more than five days suggests hemolysis, hypoxic stress or acute infections. ${ }^{24}$ Erythrocytes of newborns show additional morphologic differences of biconcave discs relative to stomatocytes is reduced in neonates ( $43 \%$ discs, $40 \%$ stomatocytes) compared with adults (78\% discs, $18 \%$ stomatocytes). ${ }^{16}$ In healthy infants there may be mild anisocytosis and poikilocytosis. Three to five percent of the red cells may be fragments, target cells, or distorted. In addition, increased numbers of pitted cells, echinocytes, spherocytes and other abnormally shaped erythrocytes are seen in neonates. The number of these "dysmorphic" cells is even higher in premature infants. Ceriotti ${ }^{25}$ found $40 \%$ discs, $30 \%$ stomatocytes and $27 \%$ additional poikilocytes in premature infants. ${ }^{25}$

\section{Reticulocyte count}

An apparent reticulocytosis exists during gestation, decreasing from $90 \%$ reticulocytes at 12 weeks' gestation, to $15 \%$ at 6 months gestation and ultimately to $4 \%$ to $6 \%$ at birth. Reticulocytosis persists for about 3 days after birth and then declines abruptly to $0.8 \%$ reticulocytes on postnatal day 4 to 7 . At 2 months, the number of reticulocytes increases slightly followed by a slight decline from 3 months to 2 years as shown in Table 2, when adult levels of $0.5 \%$ to $1.5 \%$ are attained. ${ }^{16}$ The reticulocyte count of premature infants is typically higher than that of term infants, premature infants at birth had lower hemoglobin levels, higher reticulocyte counts and higher nucleated red cell counts than the term infants. The reticulocyte counts of premature infants are inversely proportional to their gestational age, with a mean of $8 \%$ reticulocytes evident at 32 weeks gestation and $4-5 \%$ at term. Infants who are small for their gestational ages have higher red cell counts, hematocrit levels and hemoglobin concentrations compared to infants whose size is appropriate for their gestational age. ${ }^{1}$ However, the count can vary dramatically depending upon how ill the newborn is. Significant polychromasia seen on a Wright-stained blood film is indicative of postnatal reticulocytosis.

\section{Hemoglobin}

Hemoglobin synthesis results from an orderly evolution of a series of embryonic, fetal and adult hemoglobins. At birth $\mathrm{Hb} \mathrm{F}$ constitutes $70 \%$ to $80 \%$ of the total hemoglobin. $\mathrm{Hb} \mathrm{F}$ declines from $90 \%$ to $95 \%$ at 30 weeks' gestation to approximately $7 \%$ at 12 weeks after birth and stabilizes at $3.2 \pm 2.1 \%$ at 16 to 20 weeks after birth. The switch from $\mathrm{Hb} \mathrm{F}$ to $\mathrm{Hb} \mathrm{A}$ is genetically controlled and determined by gestational age; it does not appear to be influenced by the age at which birth occurs ${ }^{16}$ provides an in-depth discussion of the ontogeny, structure and types of hemoglobin. The concentration of hemoglobin fluctuates dramatically in the weeks and months after birth as a result of physiologic changes and various factors must be considered when analyzing pediatric hematologic values. The site of sampling, gestational age and time interval between delivery and clamping of the umbilical cord can influence the hemoglobin level in newborn infants. In addition, there are significant differences between capillary and venous blood hemoglobin levels. Capillary samples in newborns generally have a higher hemoglobin concentration than venous samples, which can be attributed to circulatory factors. Racial differences must also be considered when evaluating hemoglobin levels in children. African American children have hemoglobin levels averaging $0.5 \mathrm{~g} / \mathrm{dL}$ lower than those in white children. The average hemoglobin for a full-term infant at birth is 16.5 to $21.5 \mathrm{~g} / \mathrm{dL}$; levels less than $14 \mathrm{~g} / \mathrm{dL}$ are considered abnormal. The average hemoglobin value for a preterm infant who is small for gestational age is $17.1 \mathrm{~g} /$ $\mathrm{dL}$, lower than that for a full-term infant; hemoglobin values less than $13.7 \mathrm{~g} / \mathrm{dL}$ are considered abnormal in preterm infants. ${ }^{1,16}$

\section{Hematocrit}

The average hematocrit (Hct) at birth for full-term infants is $53 \%$ (range, $48 \%$ to $68 \%$ ). Frequently, newborns with increased hematocrits, especially values greater than $65 \%$, experience hyper viscosity of the blood. This can cause problems in producing a high-quality peripheral blood film. The hematocrit usually increases approximately $5 \%$ during the first 48 postnatal hours; this is followed by a slow linear decline to $46 \%$ to $62 \%$ at 2 weeks and $32 \%$ to $51 \%$ between the second and fourth months. Normal adult values of $47 \%$ for males and $42 \%$ for females are achieved during adolescence. Verylow-birth-weight preterm infants are frequently anemic at birth. Many require transfusions or erythropoietin injections or both. ${ }^{16}$

\section{Red blood cell indices}

Red cell indices, red blood cell count, hemoglobin and hematocrit in cord blood at term fall after delivery; this reflects perinatal events, the amount of blood transferred from the placenta to the infant after delivery. Delay of cord clamping may increase the blood volume and red cell mass of the infant. The mean total blood volume after birth is $86.3 \mathrm{ml} / \mathrm{kg}$ for the term infant and $89.4 \mathrm{ml} / \mathrm{kg}$ for the premature infant. The blood volume per kilogram decreases over the weeks, reaching a mean value of about $65 \mathrm{ml} / \mathrm{kg}$ by 3 to 4 months of age. Normally the hemoglobin and hematocrit values rise in the first several hours after birth because of the movement of plasma from the intravascular to the extra vascular space. ${ }^{1,26}$ Venous hemoglobin concentrations of less than $14 \mathrm{~g} / \mathrm{dl}$ in a term infant and/or a fall in hemoglobin or hematocrit level in the first day of life are abnormal. Capillary hematocrit values in newborns are higher than those in simultaneous venous samples; this difference reflects circulatory factors and is greater in preterm and sick infants. The RBC indices and RBC distribution width (RDW) provide a means for assessing and defining anemia.

The hemoglobin levels of premature infants are typically $1 \mathrm{~g} / \mathrm{dL}$ or more below the values of full-term infants. Thereafter, a gradual recovery occurs, which results in values approximating those of normal full-term infants by about 1 year of age. Very-low-birth-weight infants (less than $1500 \mathrm{~g}$ ) show a progressive decline in hemoglobin, $\mathrm{RBC}$ count, mean cell volume (MCV), mean cell hemoglobin (MCH) and mean cell hemoglobin concentration (MCHC) and have a slower recovery than other preterm and term infants. ${ }^{27}$ 


\section{Mean cell volume}

The erythrocytes of newborn infants are markedly macrocytic at birth, with a mean cell volume (MCV) in excess of $110 \mathrm{fl} / \mathrm{cell}$. The MCV begins to fall after the first week, reaching adult values by the ninth week. The average MCV for full-term infants is $110 \pm 15 \mathrm{fL}$; however, a sharp decrease occurs during the first 24 hours of life. The $\mathrm{MCV}$ continues to decrease to $90 \pm 12 \mathrm{fL}$ in 3 to 4 months. The more premature infant higher the MCV. A newborn with an MCV of less than $94 \mathrm{fL}$ should be evaluated for $\alpha$-thalassemia or iron deficiency. ${ }^{1,16}$

\section{Mean cell hemoglobin}

$\mathrm{MCH}$ is 30 to $42 \mathrm{pg}$ in healthy neonates and 27 to $41 \mathrm{pg}$ in premature infants. ${ }^{16}$

\section{Mean cell hemoglobin concentration}

The average $\mathrm{MCHC}$ is the same for full-term infants, premature infants and adults, approximately $33 \mathrm{~g} / \mathrm{dL} .^{16}$

\section{Red Blood Cell Distribution Width (RDW)}

RDW is markedly elevated in newborns, with a range of $14.2 \%$ to $17.8 \%$ the first 30 days of life. After that it gradually decreases and reaches normal adult levels by 6 months of age. ${ }^{16}$

\section{Physiologic anemia of the neonate}

Erythropoietin and Physiologic Anemia of the Newborn Erythropoietin is the primary regulator of erythropoiesis. While erythropoietin is present in cord blood, it falls to undetectable levels after birth in healthy infants. Subsequently, the reticulocyte count falls to less than one percent by the sixth day of life. The red cell, hemoglobin and hematocrit values decrease only slightly during the first week but decline more rapidly in the following 5 to 8 weeks, producing the physiologic anemia of the newborn. ${ }^{1}$ Infants born prematurely also experience a decrease in hemoglobin concentration, which is termed physiologic anemia of prematurity. ${ }^{28}$ A decrease in hemoglobin, a reduction in the number of RBCs, a decrease in the reticulocyte percentages and undetectable levels of erythropoietin associated with the transition from the placenta to the lungs as a source of oxygen. When the hemoglobin concentration decreases to approximately $1 \mathrm{~g} / \mathrm{dL}$, erythropoietic activity begins to increases until it reaches its adult levels by 14 years of age ${ }^{16}$ however, erythropoietin does not rise until the hemoglobin falls to about $9.5 \mathrm{~g} / \mathrm{dl}$. Also contributing to the physiologic anemia is the shortened life span of the fetal RBC. Studies of chromium-labeled newborn RBCs estimate a survival time of 60 to 70 days with correction for the elution rate of chromium from newborn cells. ${ }^{23}$ The life span of RBCs in premature infants is about 35 to 50 days. The more immature infant greater the degree of reduction. ${ }^{16}$ When the lungs replace the placenta as the source of oxygen, the increased oxygen saturation of the blood may generate a negative feedback response, slowing erythropoietin production. This physiologic anemia is not known to be associated with any abnormalities in the infant. Corresponding to the recovery from physiologic anemia, if there is sufficient stimulus, such as hemolytic anemia or cyanotic heart disease, the newborn infant is able to produce erythropoietin during the first several months of life. Hemo dilution related to the increased blood volume that accompanies the rapid weight gain seen in the first few months of life is not thought to play a key role in the anemia. The hemoglobin levels of premature infants are typically $1 \mathrm{~g} / \mathrm{dL}$ or more below the values of full-term infants. Thereafter, a gradual recovery occurs, which results in values approximating those of normal full-term infants by about 1 year of age. Very-low-birth-weight infants (less than $1500 \mathrm{~g}$ ) show a progressive decline in hemoglobin, $\mathrm{RBC}$ count, mean cell volume $(\mathrm{MCV})$, mean cell hemoglobin $(\mathrm{MCH})$ and mean cell hemoglobin concentration (MCHC) and have a slower recovery than other preterm and term infants. ${ }^{1}$

\section{Anemia in infants and children}

Nutritional deficiencies in infants and children can result in iron deficiency anemia and rarely in megaloblastic anemia, particularly in low-birth-weight and premature infants. This anemia is associated with abnormal psychomotor development. However, they can easily be treated with dietary fortification. ${ }^{16}$

\section{Iron deficiency anemia}

Iron deficiency anemia is the most common pediatric hematologic disorder and the most frequent cause of anemia in childhood. The occurrence of iron deficiency anemia in infants has decreased in the United States due to iron fortification of infant formula and increased rates of breast feeding. However, the prevalence is still $2 \%$ in toddlers 1 to 2 years of age and $3 \%$ in children 3 to 5 years of age and is related to early introduction and excessive intake of whole cow's milk. ${ }^{16}$

\section{Ancillary tests for anemia in infants and children}

The differential diagnosis of anemia in infants and children relies on a variety of ancillary tests. The reference ranges for a number of these tests differ from those for adults. Haptoglobin levels are so low as to be undetectable in neonates, which makes it unreliable as a marker of infant hemolysis. Transferring levels are also lower in neonates, increasing rapidly after birth and reaching adult values at 6months. Both serum ferritin and serum iron are high at birth, rise during the first month, drop to their lowest level between 6months and 4years of age and remain low throughout childhood. ${ }^{16}$ Consideration of these differences is important when interpreting hematology laboratory results for infants and children.

\section{Blood viscosity}

The viscosity of blood increases logarithmically in relation to the hematocrit. Hyper viscosity has been found in 5 percent of infants and 18 percent of infants who are small for gestational age. Newborn infants with hematocrit values of greater than 65 to 70 percent may become symptomatic because of increased viscosity of 45 infants with documented hyper viscosity and a mean hematocrit greater than 65 percent, 17 (38\%) had symptoms of irritability, hypotonia, tremors or poor suck reflex. Partial plasma exchange transfusion reduced blood viscosity, improved cerebral blood flow and relieved the symptoms. However, cerebral blood flow was normal in the asymptomatic infants with hyper viscosity and there consequently was no benefit from exchange transfusion. ${ }^{1}$

\section{Red cell antigens}

The blood group antigens on neonatal red cells differ from those of the older child and adult. The I antigen is expressed strongly while the I antigen and the A and B antigens are expressed only weakly on neonatal red cells. The I antigen is a straight-chain carbohydrate which is replaced by the branched-chain derivative, I antigen, as a result of the developmental acquisition of a glycosyl transferase. By one year of age the I antigen has become undetectable and the $\mathrm{ABH}$ antigens increase to adult levels by age 3. The ABH, Kell, Duffy and Vel 
antigens can be detected on the cells of the fetus in the first trimester and are present at birth. The Lua and Lub antigens also are detectable on fetal red cells and are more weakly expressed at birth, increasing to adult levels by age 15 . The $\mathrm{Xg}$ antigen is variably expressed in the fetus and is weaker on newborn than adult red cells. Moreover, particularly poor expression of $\mathrm{Xg}$ has been noted in newborns with trisomy 13, 18 and $21 .{ }^{1}$ The Lewis group (Lea/Leb) antigens are adsorbed on the red cell membrane and become detectable within 1 to 2 weeks after birth as the receptor sites develop. Anti-A and anti-B as iso-hemagglutinins develop during the first 6 months of life, reaching adult levels by 2 years of age.

\section{Red cell functions}

Oxygen affinity of cord blood is greater than that of maternal blood, since the affinity of $\mathrm{Hb} \mathrm{F}$ for 2,3-bisphosphoglycerate (2,3BPG) is less than that of $\mathrm{Hb} \mathrm{A}$. Levels of 2,3-BPG are lower in newborn red cells than in adult cells and even more decreased in the red cells of premature infants and this low 2,3-BPG level further heightens the oxygen affinity of newborn red cells. Thus, the red cell oxygen equilibrium curve of the newborn is shifted to the left of that of the adult. The mean partial pressure of oxygen at which hemoglobin is 50 percent saturated with oxygen at 1 day of age in term infants is $19.4 \pm 1.8$ torr, as compared with the normal adult value of $27.0 \pm 1.1$ torr. These results in a decrease in the oxygen released at the tissue level. As the $\mathrm{PO}_{2}$ falls from 90 torr in arterial to 40torr in the venous blood, $3.0 \mathrm{ml} / \mathrm{dl}$ of oxygen are released from newborn blood, while $4.5 \mathrm{ml} / \mathrm{dl}$ are released from adult, $\mathrm{Hb}$ A-containing blood. The shift to the left of the oxygen equilibrium curve is even more pronounced in the premature infant, requiring a larger fall in $\mathrm{PO}_{2}$ to release an equivalent amount of oxygen. After birth the oxygen equilibrium curve shifts gradually to the right, reaching the position of the adult curve by 6 months of age. The position of the curve in the premature infant correlates with gestational age rather than with postnatal age and its shift to the adult position is more gradual. ${ }^{1}$

\section{Red blood cell metabolism}

Enzyme activity: Many differences have been found between the metabolism of the red cells of newborn infants and that of adults. Some of the differences may be explained by the younger mean cell age in the newborn, but others seem to be properties of the fetal cell. The glucose consumption in newborn cells is lower than that in adult cells. Elevated levels of glucose phosphate isomerase, glyceraldehyde-3phosphate dehydrogenase, phosphor glycerate kinase and enolase beyond those explainable by the young cell age have been found in neonatal cells. The level of phosphor fructokinase is low in red cells of term and premature infants. The pentose phosphate shunt is active in red cells of term and premature infants, but there is glutathione instability and a heightened susceptibility to oxidant injury. Furthermore, there is relative instability of the 2,3-BPG concentration. Lower-than-adult activities have been found for several other red cell enzymes, including NADP-dependent methemoglobin reductase and glutathione peroxidase. The levels of ATP and ADP are higher in the red cells of term and preterm infants but may merely reflect the younger age of the erythrocyte population.

Membrane activity: Membrane of the newborn red cell is different from that of the adult red cell. Ouabain-sensitive ATPase is decreased and active potassium influx is significantly less in neonatal red cells. Newborn cells are more sensitive to osmotic hemolysis and to oxidant injury than are adult cells. Newborn red cell membranes have higher total lipid, phosphor lipid and cholesterol per cell than adult red cells. The patterns of phosphor lipid and phosphor lipid fatty acid composition also differ from those in adult red cells. Red cells of newborns have the same pattern of membrane proteins on poly acryl amide gel electrophoresis and the same rate of mobility in an electric field as do red cells from adults. After trypsin treatment of newborn and adult cells, however, there is a difference in electrophoretic mobility, indicating that the surface trypsin-resistant proteins are different. ${ }^{1}$

\section{White blood cell values in the newborn}

Fluctuations in the number of WBCs are common at all ages but are greatest in infants. Leukocytosis is typical at birth for full-term and preterm infants, with a wide range of normal. There is an excess of segmented neutrophils and bands and an occasional metamyelocyte, with no evidence of disease. During the subsequent days the leukocyte count continues to decrease as shown in Table 4, the trend continues until fourth year. Neutrophilic leukocytes of Term and preterm infants show a greater absolute neutrophil count than of older children, who normally maintain higher lymphocytes. The neutrophilic leukocyte count rises within the first 12 hours following birth, decreases between 1 month and 1 year and then gradually increases to stabilize at $4.4 \times 10^{9} / \mathrm{L}$ at about 4 years of age. ${ }^{22}$

Table 4 Neutrophil and band count for newborns during the first 2 days of life

\begin{tabular}{lll}
\hline Age & $\begin{array}{l}\text { Absolute neutrophil } \\
\text { count }\left(\times 10^{9} / \mathrm{L}\right)\end{array}$ & $\begin{array}{l}\text { Absolute band } \\
\text { count }\left(\times 10^{9} / \mathrm{L}\right)\end{array}$ \\
\hline Birth & $3.5-6.0$ & 1.3 \\
I2hrs & $8.0-15.0$ & 1.3 \\
$24 \mathrm{hrs}$ & $7.0-13.0$ & 1.3 \\
$36 \mathrm{hrs}$ & $5.0-9.0$ & 0.7 \\
$48 \mathrm{hrs}$ & $3.5-5.2$ & 0.7 \\
\hline
\end{tabular}

\section{Neutrophilic leukocytes}

Term and premature infants show a greater absolute neutrophil count than that found in older children, who characteristically maintain a predominance of lymphocytes. Band forms are also higher for the first 3 to 4days after birth as shown in Table 4. Newborn females have neutrophil counts averaging 2000cells/mcL higher than those of males; neonates whose mothers have undergone labor have higher counts than neonates delivered by cesarean section with no preceding maternal labor. There is some evidence that absolute neutrophil counts are lower in healthy black children than in white children. ${ }^{16}$

\section{Premature infants}

At birth, preterm infants exhibit a left shift, with promyelocytes and myelocytes frequently observed. The trend to lymphocyte predominance occurs later than in full-term infants. The neutrophil counts in premature infants are similar to or slightly lower than the neutrophil counts in full-term infants during the first 5 days of life; however, the count gradually declines to $2.5 \times 10^{9} / \mathrm{L}\left(1.1\right.$ to $\left.6.0 \times 10^{9} / \mathrm{L}\right)$ at 4 weeks as shown in Table 1 . There is no significant difference in the neutrophil count of infants by birth weight or gestational age; however, very-low-birth-weight infants have a significantly lower limit $\left(1 \times 10^{9} / \mathrm{L}\right)$ compared with larger infants. ${ }^{16}$

Neutropenia: Neutropenia is defined as a reduction in the number of circulating neutrophils to less than $1.5 \times 10^{9} / \mathrm{L}$. Neutropenia accompanied by bands and metamyelocytes is often associated with 
infection, particularly in preterm neonates. Neutropenia represents a decrease in neutrophil production or an increase in consumption. ${ }^{16}$

Neutrophilia: Neutrophilia refers to an increase in the number of neutrophils to greater than $8 \times 10^{9} / \mathrm{L}$. Morphologic changes associated with infection include Döhle bodies, vacuoles and toxic granulation. ${ }^{16}$ Normal values were obtained from the assessment of 3100 separate white blood cell counts obtained from 965 infants; 513 counts were

Table 5 Total and differential white cell count on Days I, 3 and Week 6 from infants considered to be completely normal at the time the count was obtained and for the preceding and subsequent 48hours. There was no difference in the normal ranges when values were stratified by infant birth weight or gestational age. ${ }^{24}$

Eosinophils and basophils: The percentages of eosinophils and basophils remain consistent throughout infancy and childhood as shown in Table 5 \& 6

\begin{tabular}{|c|c|c|c|}
\hline Parameters & Day I (n= I80) Mean \pm SD(Range) & Day 3(n=I73) Mean \pm SD(Range) & Week 6(n=|42) Mean \pm SD(Range) \\
\hline TWBC(x 109/L) & $10.8 \pm 15.0(3.5-25.0)$ & $10.7 \pm 3.8(3.5-24.3)$ & $8.8 \pm 2.8(3.9-17.4)$ \\
\hline Neutr(\%TWBC) & $56.8 \pm 10.9(22.0-76.0)$ & $46.9 \pm 12.9(\mid 1.0-90.0)$ & $34.6 \pm \mid I .5(\mid 4.0-78.0)$ \\
\hline Lymph(\%TWBC) & $38.7 \pm 10.9(16.0-70.0)$ & $50.7 \pm 12.9(10.0-89.0)$ & $63.4 \pm I I .3(22.0-86.0)$ \\
\hline Baso(\%TWBC) & $0.0 \pm 0.0(0.0)$ & $0.0 \pm 0.0(0.0)$ & $0.0 \pm 0.0(0.0)$ \\
\hline Mono(\% TWBC) & $4.3 \pm 3.2(0.0-12.0)$ & $2.2 \pm 2.7(0.0-11.0)$ & $1.9 \pm 2.6(0.0-12.0)$ \\
\hline Eosin(\% TWBC) & $0.2 \pm 0.6(0.0-4.0)$ & $0.3 \pm 0.9(0.0-6.0)$ & $0.4 \pm 0.8(0.0-5.0)$ \\
\hline
\end{tabular}

TWBC, total white blood cells count; Neutr, neutrophils; Lymph, lymphocytes; Baso, basophils; Mono, monocytes; Eosin, esoinophils²

Table 6 Normal leukocyte counts

\begin{tabular}{|c|c|c|c|c|c|c|c|c|c|c|c|c|}
\hline \multirow{2}{*}{ Age } & \multicolumn{2}{|c|}{ TWBC } & \multicolumn{3}{|c|}{ Neutrophils } & \multicolumn{3}{|c|}{ Lymphocytes } & \multicolumn{2}{|c|}{ Monocytes } & \multicolumn{2}{|c|}{ Eosinophils } \\
\hline & Mean & Range & Mean & Range & $\%$ & Mean & Range & $\%$ & Mean & $\%$ & Mean & $\%$ \\
\hline Birth & - & - & 4 & $2.0-6.0$ & - & 4.2 & $2.0-7.3$ & - & 0.6 & - & 0.1 & - \\
\hline $12 \mathrm{hrs}$ & - & - & 11 & $7.8-14.5$ & - & 4.2 & $2.0-7.3$ & - & 0.6 & - & 0.1 & - \\
\hline $24 \mathrm{hrs}$ & - & - & 9 & $7.0-12.0$ & - & 4.2 & $2.0-7.3$ & - & 0.6 & - & 0.1 & - \\
\hline $1-4 w k$ & - & - & 3.6 & I.8-5.4 & - & 5.6 & $2.9-9.1$ & - & 0.7 & - & 0.2 & - \\
\hline $6 \mathrm{mth}$ & 11.9 & $6.0-17.5$ & 3.8 & $1.0-8.5$ & 32 & 7.3 & $4.0-13.5$ & 61 & 0.6 & 5 & 0.3 & 3 \\
\hline lyr & 11.4 & $6.0-17.5$ & 3.5 & $1.5-8.5$ & 31 & 7 & $4.0-10.5$ & 61 & 0.6 & 5 & 0.3 & 3 \\
\hline $2 y \mathrm{rs}$ & 10.6 & $6.0-17.0$ & 3.5 & $1.5-8.5$ & 33 & 6.3 & $3.0-9.5$ & 59 & 0.5 & 5 & 0.3 & 3 \\
\hline 4yrs & 9.1 & $5.5-15.5$ & 3.8 & $1.5-8.5$ & 42 & 4.5 & $2.0-8.0$ & 50 & 0.5 & 5 & 0.3 & 3 \\
\hline 6yrs & 8.5 & $5.0-14.5$ & 4.3 & $1.5-8.0$ & 51 & 3.5 & I.5-7.0 & 42 & 0.4 & 5 & 0.2 & 3 \\
\hline 8yrs & 8.3 & $4.5-13.5$ & 4.4 & $1.5-8.0$ & 53 & 3.3 & $1.5-6.8$ & 39 & 0.4 & 4 & 0.2 & 2 \\
\hline $10 y r s$ & 8.1 & $4.5-13.5$ & 4.4 & I.8-8.0 & 54 & 3.1 & $1.5-6.5$ & 38 & 0.4 & 4 & 0.2 & 2 \\
\hline $16 y r s$ & 7.8 & $4.5-13.0$ & 4.4 & I.8-8.0 & 57 & 2.8 & $1.2-5.2$ & 35 & 0.4 & 5 & 0.2 & 3 \\
\hline $21 y r s$ & 7.4 & $4.5-11.0$ & 4.4 & I.8-7.7 & 59 & 2.5 & I.0-4.8 & 34 & 0.3 & 4 & 0.2 & 3 \\
\hline
\end{tabular}

Lymphocytes: Lymphocytes constitute about $30 \%$ of the leukocytes at birth and increase to $60 \%$ at 4 to 6 months. They decrease to $50 \%$ by 4 years, to $40 \%$ by $6 y e a r s$ and to $30 \%$ by 8 years as shown in Table $1,5 \& 6$. Benign immature B cells (hematogones), although predominantly found in the bone marrow, can sometimes be seen in the peripheral blood of newborns. These lymphocytes are primarily mid-stage B cells and are frequently referred to as "baby" or "kiddie" lymphocytes. They vary in size from 10 to $20 \mu \mathrm{m}$, have scant cytoplasm and condensed but homogeneous nuclear chromatin and may have small, indistinct nucleoli. Although these lymphocytes may be similar in appearance to the malignant cells seen in childhood acute lymphoblastic leukemia (ALL), these benign cells lack the asynchronous or aberrant antigen expression seen in ALL and thus can be differentiated from the lymphocytes of infant ALL by immune phenol typing. ${ }^{16}$
Monocytes: The mean monocyte count of neonates is higher than adult values. At birth the average proportion of monocytes is $6 \%$. During infancy and childhood, an average of $5 \%$ is maintained as shown in Table $1 \& 6$ except in the second and third weeks, when the proportion increases to around $9 \%$. The count reaches adult levels at 3 to 5 months. Numbers of TWBCs are $\times 10^{9} / \mathrm{L}$, ranges are estimates of $95 \%$ confidence limits and percentages refer to differential counts. Neutrophils include band cells at all ages and a small number of metamyelocytes and myelocytes in the first few days of life. Dashes indicate insufficient data for a reliable estimate. ${ }^{26}$

\section{Neonatal hematologic response to infection}

Sepsis in neonates is a common cause of morbidity, particularly in premature and low-birth-weight infants. Defective B-cell response against polysaccharide agents as well as abnormal cytokine release 
by neutrophils and monocytes has been implicated. Because of the transient neutrophilia that occurs during the first 24hours after birth, followed by a rapid decline, the neutrophil count is not a satisfactory index of infection in the newborn. Newborns with bacterial infections frequently have normal or below normal neutrophil counts with a shift to the left. Thus, many practitioners depend upon the band count and its derived immature-to-total neutrophil ratio as an indicator of sepsis in neonates, although CD64, C-reactive protein and procalcitonin levels have been suggested as more sensitive markers of sepsis in infants and children. ${ }^{16}$

\section{Platelet values in the newborn}

The platelet count usually ranges from 150 to $400 \times 10^{9} / \mathrm{L}$ for fullterm and preterm infants, comparable to adult values. Platelet counts generally increase in both term and preterm infants in the first few months of life, as evidenced by increased mean platelet volume the first month of life as shown in Table 7. Low normal platelet counts have been associated with birth trauma, thrombocytopenia of fewer than $100 \times 10^{9}$ platelets/L may be seen in high-risk infants with sepsis or respiratory distress and neonates with trisomy syndromes and investigation should be undertaken for underlying pathology. Platelets of a newborn infant show great variation in size and shape. Adult reference ranges are achieved by 6 months of age. Thrombocytopenia in premature infants should be considered abnormal not physiologic. ${ }^{22}$

Table 7 Normal platelet counts for full-term and preterm infants

\begin{tabular}{ll}
\hline Age & Platelet count $\left(\times 10^{\circ} /\right.$ L; Mean \pm I SD) \\
\hline Preterm infants, 27-3 I weeks & $275.0 \pm 60.0$ \\
Preterm infants, 32-36weeks & $290.0 \pm 70.0$ \\
Term infants & $310.0 \pm 68.0$ \\
Normal Child/Adult & $300.0 \pm 50.0$
\end{tabular}

SD, standard deviation; Adapted from Oski FA, Naiman JL, Normal blood values in the newborn period ${ }^{29}$

\section{Neonatal hemostasis}

The physiology of the hemostatic system in infants and children is different from that in adults. The vitamin K-dependent coagulation factors (factors II, VII, IX and X) are at about $30 \%$ of adult values at birth; they reach adult values after 2 to 6 months, although the mean values remain lower in children than in adults. Levels of factor XI, factor XII, prekallikrein and high-molecular-weight kininogen are between $35 \%$ and $55 \%$ of adult values at birth, reaching adult values after 4 to 6 months. In contrast, the levels of fibrinogen, factor VIII and von Willebrand factor are similar to adult values throughout childhood. ${ }^{16}$ Factor $\mathrm{V}$ decreases during childhood, with lower levels during the teen years as compared with adults. The physiologic anticoagulants and inhibitors of coagulation-protein $C$, protein $S$, antithrombin and a disintegrin-like and metallo-protease domain with thrombospondin type 1 motifs 13 (ADAMTS 13)-are reduced to about $30 \%$ to $40 \%$ at birth. Antithrombin reaches adult values by 3 months, whereas protein $\mathrm{C}$ does not normalize until after 6 months. In the fibrinolytic system, levels of plasminogen and $\alpha_{2}$-antiplasmin are similar to adult levels at birth, whereas levels of tissue plasminogen activator are low and levels of plasminogen activator inhibitor (PAI) are increased. ${ }^{16}$ The hemostatic components are not only changing in concentration over the first few weeks to months of life, but their values are also dependent upon the gestational age of the child and premature infants have different values at birth than term infants.

\section{Aging process and hematopoiesis}

The hematopoietic system is modestly affected by aging and these effects become particularly notable after age 65 . There is a continuous decrease in the volume of the hematopoietic marrow with age, which does not cause significant alterations in either granulocyte, monocyte or platelet counts, although a slight decrease in population mean hemoglobin concentration in men occurs. The recruitment of neutrophils in response to exogenous stimuli is slightly decreased, but the response to infection does not appear impaired. Neutrophil function is not significantly decreased with age of the subject. Although the population mean vitamin $\mathrm{B}_{12}$ and folate levels decrease with age, these changes do not result in decreased hematopoiesis as judged by blood counts, except in individual patients with significant deficiencies. ${ }^{1}$ Anemia in older individuals should be evaluated in the same manner as anemia in younger individuals. Certain coagulation proteins are altered significantly with aging and a propensity to accelerated coagulation and compensatory fibrinolysis is present, leading to a new steady state. Decreased immune cell function is the most consistent change in older persons and perhaps the most important functionally. Although there is a tendency to decreased lymphocyte counts in the blood, the major effects are mediated by dysregulation of $\mathrm{T}$ lymphocyte function, perhaps as a result of the prolonged period since thymic atrophy in older subjects. This change affects both cellular immune functions and antibody responses to antigens because of the $\mathrm{T}$ helper cell function required. However, The aging process is associated with the functional decline of several organ systems, such as cardiovascular, renal, musculo-skeletal, pulmonary and bone marrow reserve. ${ }^{30}$ Certain cells lose their ability to divide (example nervous tissue and muscles) whereas bone marrow and the gastrointestinal mucosa, remain mitotic. Marrow cellularity begins at $80 \%$ to $100 \%$ in infancy and decreases to about $50 \%$ after 30 years, followed by a decline to $30 \%$ after age 65 years. ${ }^{31}$

\section{Marrow cellularity}

The cellularity of the marrow decreases with aging, as estimated from studies of histologic sections and magnetic resonance imaging confirms an age-related reduction in marrow cellularity. Studies of marrow from the anterior iliac crest demonstrate a progressive decrease in cellularity from $80-100$ percent to about 50 percent over the first 30 years of life. Cellularity of about 40 percent has been found in sternal marrow from normal adults. In iliac crest marrow there is a plateau of about 50 percent cellularity to age 65 , after which a decrease in cellularity to about 30 percent occurs over the succeeding decade. ${ }^{1}$ This latter decline may be due to an increase in fat related to osteoporosis, with reduction of the volume of cancellous bone, rather than to a decrease in hematopoietic cells. These changes may account for the more pronounced marrow hypocellularity in the subcortical zone.

\section{Assessment of hematologic parameters in healthy elderly adults}

Anemia and the elderly: The World Health Organization defines anemia as hemoglobin less than $13 \mathrm{~g} / \mathrm{dl}$ in males and less than $12 \mathrm{~g} / \mathrm{dl}$ in females. Based on this definition, the prevalence of anemia in males older than 85 years is approximately $44 \% .{ }^{14}$ It is unclear however, if the low $\mathrm{Hb}$ levels observed in the elderly are due to disease or normal changes related to aging. Most elderly persons maintain a normal blood count and elderly individuals with low Hb levels have an underlying health problem. The variables contributing to anemia are a decrease in bone marrow function, a decline in physical activity, cardiovascular 
disease and chronic inflammatory disorders. Most studies have shown that the mean hemoglobin level or hematocrit for a population of men falls slightly after middle age, mean hemoglobin levels decrease by less than $1.0 \mathrm{~g} / \mathrm{d}$ in the sixth through eighth decades. ${ }^{1}$ In a group of men age 96 to 106 years the mean hemoglobin level was $12.4 \mathrm{~g} /$ $\mathrm{dl}$, but a later report of centenarians did not find a decrease in mean hemoglobin as compared with other men. In a group of men aged 84 to 98 years the mean hemoglobin level was $14.8 \mathrm{~g} / \mathrm{dl}$, only $0.8 \mathrm{~g} / \mathrm{dl}$ less than that of a younger comparison group. The lowest levels, however, are found in the oldest patients. The hemoglobin levels in women may increase slightly with age or remain unchanged. The narrowing of the difference in hemoglobin level between older men and woman may be the result of decreased androgen levels in older men and decreased estrogen levels in older women. However, shortened red cell survival may play a role in the unexplained mild decrease in hemoglobin concentration in some older individuals. To lesser degree, the elderly are prone to anemias such as sideroblastic, aplastic, hemolytic, myelophthisic or anemia due to protein calorie malnutrition. Hypo proliferation or decreased production of $\mathrm{RBCs}$ is a common form of anemia in the elderly. Initially, this form of anemia was called unexplained anemia, senile anemia and anemia of senescence. Hypo proliferative anemia often occurs secondary to iron deficiency, vitamin $\mathrm{B}_{12}$ or folate deficiency, renal failure, hypothyroidism, chronic inflammation or endocrine disease ${ }^{14}$ Often the etiology of anemia in the elderly cannot be determined. However, Iron deficiency and the anemia of chronic disease have usually been responsible for low hemoglobin levels in the majority of asymptomatic elderly people. Iron absorption is not impaired in the elderly, but utilization of orally administered iron for hemoglobin production is reduced. Since hemoglobin concentration does not decrease significantly with age, elderly patients with anemia should be evaluated for a cause (iron, folate, or vitamin $\mathrm{B}_{12}$ deficiency or underlying malignancy or renal disease, etc.) before ascribing it to age.

Erythrocyte sedimentation rate and $\mathbf{C}$ reactive protein: The erythrocyte sedimentation rate increases significantly with age. Mean values of $14 \mathrm{~mm} / \mathrm{h}$ (Western green) and individual values as high as $69 \mathrm{~mm} / \mathrm{h}$ were found in apparently well women age 70 to $89 y$ years who were followed for 3 to 11years. The erythrocyte sedimentation rate is of limited value in detecting disease in elderly patients. Estimation of levels of acute-phase proteins appears to offer no advantage over the erythrocyte sedimentation rate. The C-reactive protein content of serum also is mildly elevated in older individuals without an apparent inflammatory process.

Erythrocyte 2,3-bisphosphoglycerate concentration (2,3-BPG): The erythrocyte 2,3-bisphosphoglycerate (2,3-BPG) level has been reported to fall with age from a mean value of $14.9 \mu \mathrm{mol} / \mathrm{g}$ hemoglobin at ages 18 to 24 to $13.9 \mu \mathrm{mol} / \mathrm{g}$ hemoglobin at ages 75 to 84 . This decrease is could account for a slight increase in oxygen affinity of hemoglobin. ${ }^{1}$

\section{Osmotic fragility}

Erythrocyte osmotic fragility is increased in older individuals in comparison with younger subjects. This phenomenon is associated with an increased mean corpuscular volume $(\mathrm{MCV})$ and decreased mean corpuscular hemoglobin concentration (MCHC) of the red cells of older people.

\section{Total and differential leukocyte count}

There is no consistent, significant variation in the total white blood cell count in older subjects. Normal total white blood cell count and neutrophil counts were found in nonagenarian and centenarian populations. Some investigators have found that above age 65 the total white blood cell count tends to be lower in both sexes, due primarily to a decrease in the lymphocyte count. Others have reported a decrease in the white blood cell count due to a fall in the lymphocyte and the neutrophil count in women, but not in men, over age 50 . The absolute lymphocyte count has also been reported to be unchanged in the aged.

\section{Leukocytes and its response to infection}

Leukocyte count does not rise as high in response to infection in elderly individuals as in young people and that often the principal manifestation of a leukocyte response is an increase in the number of band forms in an otherwise normal leukocyte count. The leukocyte count and the proportion of neutrophils rise much less in response to bacterial pyrogen in individuals over age 70 than in young adults. Similarly, the neutrophilic leukocytosis that occurs 5 hours after the oral administration of $40 \mathrm{mg}$ prednisolone is diminished in patients over 55years of age. ${ }^{1}$ These observations suggest a diminished marrow granulocyte reserve in the elderly and/or a decrease in hematopoietic growth factor release. The decreased responsiveness of older individuals to granulocyte colony-stimulating factor-induced release of neutrophils from the marrow supports these suppositions. Leukocyte function and serum opsonic capacity is well preserved in elderly individuals, but defects in phagocytic ability and diminished responses to chemotactic peptides and to oxidative stress have been documented. Defects in neutrophil function in elderly subjects may be due to inhibitory substances detected in plasma. Splenic function in elderly subjects may be impaired, as evidenced by an increase in the percentage of pitted erythrocytes in the blood. In the healthy elderly with no underlying pathologic condition, there are no statistically significant differences in the total leukocyte count or WBC differential between old-old compared with middle- aged adults. ${ }^{32}$

\section{Lymphocytes}

Immune senescence, age -related defects in lymphopoiesis, affects humoral and cellular immunity. The thymus disappears by early middle age and adults depend on T lymphocyte response in the secondary tissue. ${ }^{33}$ The number of naïve $T$ cells decreases in the elderly, increasing the dependency on memory $\mathrm{T}$ cells. $\mathrm{T}$ cells of the elderly have impaired responsiveness to mitogens and antigens as a result of a decreased expression of co-stimulator CD28. B lymphocyte function depends on $\mathrm{T}$ cell interaction. When $\mathrm{T}$ cell inadequacies occur, there may be a decreased ability to generate an antibody response. ${ }^{34}$

\section{Immune responses}

Decrease in immune function mediated by lymphocytes is the most significant change with aging. Thymus involution occurs after puberty and total thymic atrophy occurs by late middle age. With these changes, thymic-mediated $\mathrm{T}$ lymphocyte development disappears and older individuals are dependent on their existing T lymphocyte pool to mediate $\mathrm{T}$ cell-dependent immune responses. In the absence of thymic function, the number of naive $\mathrm{T}$ cells decreases in older individuals and memory T cells are the predominant type. B lymphocyte function is dependent on $\mathrm{T}$ cell accessory roles and the decreased ability to generate antibody responses, especially to primary antigens, may be the result of $\mathrm{T}$ cell inadequacies rather than an intrinsic fault of $\mathrm{B}$ lymphocytes. Natural killer cells are increased in number, but their function is disturbed. Delayed hypersensitivity reactions are reduced in the elderly. These immunologic deficits are correlated with overall mortality in individuals over age 60 . Serum immunoglobulin $M$ 
and $\mathrm{G}$ concentrations do not change significantly in older subjects. Serum IgA levels increase with age. An increased prevalence of auto antibodies (e.g., anti-IgG rheumatoid factor) occurs in older people. ${ }^{1}$ Monoclonal plasma immunoglobulins (essential monoclonal gammopathy) are found with increasing frequency with age, reaching three percent in people over age 70 and nearly six percent in those from 80 to 89 (Table 8 ).

Table 8 Reference ranges of complete blood cell count in adult white persons and persons of African ancestry

\begin{tabular}{|c|c|c|c|c|}
\hline \multirow{2}{*}{ Variable } & \multicolumn{2}{|l|}{ White } & \multicolumn{2}{|l|}{ African } \\
\hline & Male & Female & Male & Female \\
\hline Hemoglobin(g/dL) & $12.7-17.0(\mid 3.5-17.5)$ & II.6-I5.6(I2.0-I5.5) & $11.3-16.4$ & $10.5-14.7$ \\
\hline $\operatorname{RBCs}\left(\times 10^{12} / \mathrm{L}\right)$ & $4.0-5.6(4.3-5.7)$ & $3.8-5.2(3.9-5.0)$ & $3.8-5.7$ & $3.6-5.2$ \\
\hline Mean corpuscular volume(fL) & $81.2-101.4(81.2-95.1)$ & $81 . I-99.8(81.6-98.3)$ & 77.4-103.7 & $74.2-100.9$ \\
\hline RBC distribution width (\%) & $(|| .8-\mid 5.6)$ & (II.9-I5.5) & & \\
\hline Platelets $\left(\times 10^{9} / \mathrm{L}\right)$ & $143-332(150-450)$ & $169-358(150-450)$ & $115-290$ & $125-342$ \\
\hline WBCs $\left(\times 10^{9} / \mathrm{L}\right)$ & $3.6-9.2(3.5-10.5)$ & $3.5-10.8(3.5-10.5)$ & $2.8-7.2$ & $3.2-7.8$ \\
\hline Neutrophils $\left(\times 10^{9} / \mathrm{L}\right)$ & I.7-6.I(I.7-7.0) & I.7-7.5(I.7-7.0) & $0.9-4.2$ & I.3-4.2 \\
\hline Lymphocytes $\left(\times 10^{9} / \mathrm{L}\right)$ & I.0-2.9(0.9-2.9) & $0.95-3.3(0.9-2.9)$ & $1.0-3.2$ & I.I-3.6 \\
\hline Monocytes(×109/L) & $0.18-0.62(0.3-0.9)$ & $0.14-0.6 \mathrm{I}(0.3-0.9)$ & $0.15-0.58$ & $0.15-0.39$ \\
\hline Eosinophils(× 10\%/L) & $0.03-0.48(0.05-0.50)$ & $0.04-0.44(0.05-0.50)$ & $0.02-0.79$ & $0.02-0.41$ \\
\hline Basophils(×10\%/L) & $(0-0.3)$ & $(0-0.3)$ & & \\
\hline
\end{tabular}

Abstracted from population-based studies from Bain and NHANES-II. Mayo Clinic normal values, based primarily on white subjects, are in parentheses for comparison. RBC, red blood cell;WBC, white blood cell ${ }^{35}$

\section{Platelets}

The platelet count does not change with age. Increased plasma levels of two platelet a-granule constituents, $\beta$-Thromboglobulin and platelet factor iv, have been found in individuals over 65years of age in comparison with younger individuals. Enhanced in vitro reactivity to platelet-aggregating agents has been observed. Decreased platelet membrane protein kinase $\mathrm{C}$ activity and translocation to the cytosol after platelet activation was noted in platelets from older subjects. ${ }^{1,36}$

\section{Plasma coagulation factors}

Plasma concentrations of factor VII coagulant activity and antigen, factor VIIIC, von Willebrand factor, fibrinogen, fibrino-peptide A and tissue plasminogen activator antigen are increased with age. Fibrinogen level has been found to be a risk factor for thrombotic vascular disease. In healthy centenarians, levels of activated factor VII, activation peptides of pro-thrombin, factors IX and $\mathrm{X}$ and thrombinanti thrombin complex concentration were increased, signs of higherthan-expected coagulation enzyme activity. Higher D-dimer and plasmin-antiplasmin complexes indicate an accompanying increase in fibrinolytic activity. Thus, coagulant and fibrinolytic activities appear to be increased in the older subjects by both in vitro and in vivo studies. ${ }^{1}$ Older patients may show an exaggerated anticoagulant response to warfarin.

\section{Hematologic neoplasia in older individuals}

Several hematologic diseases are increased in frequency with age; notable increase in clonal (neoplastic) diseases of hematopoiesis, which depicts the rate of occurrence of the leukemias (the aggregate of the four major types), lymphoma and myeloma at 5-year intervals. The inclusion of acute lymphocytic leukemia, which has a mode at about 3.5years and then increases in frequency again after middle age, does not dampen the dramatic age-dependent incidence rate. Although hematologic malignancies may occur at any age, certain disorders are common in those older than 50years. ${ }^{1}$

\section{Myelodysplastic syndrome}

Myelodysplastic syndromes a heterogenous group characterized by a defect in the hematopoietic stem cell that may affect multiple cell lineages are diagnosed more frequently in the elderly and in some patients myelodysplastic syndrome terminates in acute leukemia. ${ }^{1}$

\section{Myelo proliferative disorders}

Myelo proliferative disorders are monoclonal proliferations of hemapoietic stem cells with over accumulation of RBCs, WBCs or platelets in various combinations. The average age of patients with polycythemia vera is $60 y e a r s$. The incidence of chronic myelogenous leukemia increases after age 50. Chronic idiopathic myelofibrosis occurs in age between 50 to 70 years. ${ }^{1}$

\section{Chronic lymphocytic leukemia (CLL)}

CLL is the most common cause of lymphocytosis in the elderly and constitute $30 \%$ of all leukemia's seen in western countries. The onset is usually asymptomatic at a median age of 60 to 65 years and it occurs twice as often in males as compared with females. ${ }^{37}$

\section{Multiple myeloma}

Multiple myeloma is a plasma cell cancer characterized by monoclonal gammopathy and multifocal destructive bone lesions throughout the skeleton. The neoplastic plasma cells secret complete or incomplete immunoglobulins. The age of peak incidence for multiple myeloma is 67 years, with $80 \%$ of cases occurring after $60 y e a r s$. It occurs at an equal frequency in males and female. ${ }^{1}$ 


\section{Conclusion}

The hematological changes are obvious in both the neonates and the elderly persons and at such; different hematological variables must be implemented in various developing stages of the neonates as well as the different classes of aged elderly individuals. Also among the elderly, certain hematological disorders are more dominant and clinicians should be attentive to this.

\section{Recommendation}

Further studies should be carried out in each of the laboratories to establish their hematological reference values based on sex and age for both healthy newborn and aging instead of using published reference intervals.

\section{Acknowledgements}

None.

\section{Conflict of interest}

The author declares no conflict of interest.

\section{References}

1. Beutler E, Lichtman MA, Coller BS, et al. General hematology. Williams Hematology-part 11, USA: McGraw Hill; 2011. 40 p.

2. Ogundeyi MM, Olarewaju DM, Njokanma OF, et al. Hematological profile of apparently healthy term babies aged one day, three days and six weeks delivered in Sagamu, Nigeria. Nigerian Journal of Paediatrics. 2011;38(3):125-130

3. Onwukeme KE, Olomu IN, Nnanna OU. Hematological indices in healthy Nigerian neonates. Niger Med Pract. 1992;23:7-11.

4. Segel GB, Palis J. Haematology of the Newborn. In: Beutler E, et al. editors. Williams Haematology. 6th ed. New York, USA: McGraw-Hill; 2011. p. 77-84.

5. Ohls RK, Christensen RD. Development of the haematopoietic system. In: Behrman RE, et al. editors. Nelson Textbook of Paediatrics. 18th ed. Philadelphia W.B. USA: Saunders Company; 2007. p. 1997-2018.

6. Christensen RD. Expected hematologic values for term and preterm neonates. Hematologic problems of the neonates. Philadelphia, USA; 2000. 117 p.

7. Roberts AGI. Haematological problems of the newborn. In: McIntosh N, et al. editors. Forfar and Arneil's Textbook of Paediatrics. 6th ed. Philadelphia, USA: Churchill Livingston; 2003. p. 294-309.

8. Saleh MI, Nalbant D, Widness JA, et al. Population pharmacodynamic analysis of erythropoiesis in preterm infants for determining the anemia treatment potential of erythropoietin. Am J Physiol Regul Integr Comp Physiol. 2013;304(9):R772-R781.

9. Christensen RD, Lambert DK, Henry E, et al. End-tidal carbon monoxide as an indicator of the hemolytic rate. Blood Cells Mol Dis. 2015;54(3):292-296.

10. Urrechaga E, Borque L, Escanero JF. Erythrocyte and reticulocyte indices in the assessment of erythropoiesis activity and iron availability. Int $J$ Lab Hematol. 2013;35(2):144-149.

11. Al-Ghananim RT, Nalbant D, Schmidt RL, et al. Reticulocyte hemoglobin content during the first month of life in critically ill very low birth weigh neonates differs from term infants, children, and adults. J Clin Lab Anal. 2015;30(4):326-334.
12. Piva E, Brugnara C, Spolaore F, et al. Clinical utility of reticulocyte parameters. Clin Lab Med. 2015;35(1):133-163.

13. Older Americans: Key indicators of well being. Federal interagency forum on aging related statistics, Washington, USA; 2006.

14. Smith D. Management and treatment of anemia in the elderly. Clin Geriatr. 2002;10:8

15. Proytcheva MA. Issues in neonatal cellular analysis. Am J Clin Pathol. 2009;131(4):560-573.

16. Goossen LH. Pediatric and geriatric hematology. hematology, oncology and palliative medicine; 2015.

17. Yoder MC. Embryonic hematopoiesis. In: Christensen RD, editor Hematologic problems of the neonate. USA: Philadelphia saunders; 2002. p. 3-20.

18. Normal hematological values. Newborn services clinical guidelines, USA; 2006.

19. Al-Mufti R, Hambley H, Farzaneh F, et al. Fetal and embryonic hemoglobins in erythroblasts of chromosomally normal and abnormal fetuses at 10-40 weeks of gestation. Haematologica. 2000;85(7):690693.

20. He Z, Russell JE. Expression, purification and characterization of human hemoglobins Gower-1 (zeta(2)epsilon(2)), Gower-2 (alpha(2)epsilon(2)) and Portland-2 (zeta(2)beta(2)) assembled in complex transgenicknockout mice. Blood. 2001;97(4):1099-1105.

21. Pahal GS, Jauniaux E, Kinnon C, et al. Normal development of human fetal hematopoiesis between eight and seventeen weeks gestation. Am J Obstet Gynecol. 2000;183(4):1029-1034.

22. Henry E, Christensen RD. Reference intervals in neonatal hematology. Clin Perinatol. 2015;42(3):483-497.

23. Segal GB, Palis J. Hematology of the newborn. In: Lichtman, et al. editors. Williams hematology. 7th ed. New York, USA: Mcgraw Hill; 2006. p. 81-98.

24. Jones LL, Schwartz AL, Wilson DB. Hematologic problems in the fetus and neonate. In: Martin RJ, et al. editors. Fanaroff and Martin's neonatalperinatal medicine. 8th ed. Philadelphia, USA: Mosby Elsevier; 2006. $1310 \mathrm{p}$.

25. Ceriotti F. Pediatric References Intervals. In: Soldin SJ, et al. (Eds.), Clinical Chemistry. 5th ed. Washington, USA: AACC Press; 2005. 257 p.

26. Keohane EM, Smith L, Obladen MJW, et al. Rodak's Hematology: Clinical Principles and Applications. 5th ed. Saunders, Pennsylvania, USA; 2015.912 p.

27. Obladen M, Diepold K, Maier RF. Venous and arterial hematologic profiles of very low birth weight infants. Pediatrics. 2000;106(4):707711.

28. Cavaliere TA. Red blood cell indices: implications for practice. Newborn \& Infant Nursing Reviews. 2004;4(4):231-239.

29. Oski FA. The erythrocytes and its disorders: Hematology of infancy and childhood. 3rd ed. Saunders, New York, USA; 1993. p. 18-43.

30. Chatta GS, Dale DC. Aging and hematopoiesis: Implications for treatment with hemopoietic growth factors. Drugs Aging. 1996;9(1):37-47.

31. Lansdorp PM. Self renewal of stem cells. Biol Blood Marrow Transplant. 1997;3(4):171-178.

32. Salive ME, Huntley JC, Guralnik JM, et al. Anemia and hemoglobin level in older persons: relationship wth age gender and healthy status. $J$ Am Geriatr Soc. 1992;40(5):489-496. 
33. Globerson A. T lymphocytes and aging. Int Arch Allergy Immunol. 1995;107(4):491-497.

34. Song L, Kim YH, Chopra RK, et al. Age related effects in T cell activation and proliferation. Exp Gerontol. 1993;28(4-5):313-321.

35. Tefferi A, Hanson CA, Inwards DJ. How to interpret and pursue an abnormal complete blood cell count in adults. Mayo Clin Proc. 2005;80(7):923-936.
36. Loebenstein BG. Changes in the aging immune system. Biologicals. 1997;25(2):205-208.

37. Rozman C, Montserrat E. Chronic lymphocytic leukemia. $N$ Engl J Med. 1995;333(16):1052-1057. 